\title{
Time-lapse geophysical technology-based study on overburden strata changes induced by modern coal mining
}

\author{
Wenfeng Du $\cdot$ Suping Peng $\cdot$ Guowei Zhu $\cdot$ Feng Yang
}

Received: 13 July 2014/Revised: 5 August 2014/Accepted: 6 August 2014/Published online: 30 September 2014

(C) The Author(s) 2014. This article is published with open access at Springerlink.com

\begin{abstract}
To study the impact of modern coal mining on overlying strata and its water bearing conditions, integrated time-lapse geophysical prospecting integrating 3D seismic, electrical and ground penetrating radar method were used. Through observing and analyzing the geophysical data variations of all stages of pre-mining, mining and post-mining as well as post-mining deposition stable period, impacts of coal mining on stratigraphic structure and its water bearing were studied and modern coal mining induced stratigraphic change pattern was summarized. The research result shows that the stratigraphic structure and the water bearing of surface layer during modern coal mining have self-healing pattern with mining time; the self-healing capability of near-surface strata is relatively strong while the roof weak; water bearing selfhealing of near-surface strata is relatively high while the roof strata adjacent to mined coal beds low. Due to integrated time-lapse geophysical prospecting technology has extra time dimension which makes up the deficiency of static analysis of conventional geophysical methods, it can better highlight the dynamic changes of modern coal mining induced overburden strata and its water bearing conditions.
\end{abstract}

Keywords Time lapse $\cdot$ Geophysical prospecting $\cdot$ Coal mining $\cdot$ Overburden strata $\cdot$ Strata changes $\cdot$ Modern coal mining

\section{Introduction}

Modern coal mining organically integrates advanced coal mining equipment, advanced coal mining technologies and modern management technology, which features high mechanization, high total productivity and high intelligence and has large primary mining area, large primary mining height and large primary goaf area compared to conventional coal mining technology ( $\mathrm{Gu}$ and Zhang 2012). It is of great importance for sustainable underground water resources utilization, ecological environment protection and green mining realization to study coal mining

W. Du $(\bowtie) \cdot$ S. Peng $\cdot$ G. Zhu $\cdot$ F. Yang

State Key Laboratory of Coal Resources and Safe Mining, China University of Mining and Technology, Beijing 100083, China

e-mail: duwf66@126.com induced underground water occurrence and overburden strata evolution pattern (Gu et al. 2013; Gu 2013; Zhang et al. 2013a).

At present, reports on time-lapse geophysical monitoring technologies mainly refer to oil field time-lapse seismic technology (Zhao 2005; Wang et al. 2008). This technology firstly appeared in the middle 1990s and is mainly used for reservoir performance management monitoring, which studies changes of reservoir properties through comparing variations between seismic attributes observed in different periods. Literatures on coal mining integrating time-lapse seismic prospecting (Du and Peng 2014), time-lapse electrical prospecting (Zhang et al. 2012) and time-lapse ground penetrating radar prospecting (Zhang et al. 2013b) are mainly from the research of this project.

Time-lapse geophysical monitoring technology carries out multiple observations for the same stratum at certain time intervals to study the temporal-spatial variations of 
stratigraphic features, which can be repeated multiple 2D observations or repeated multiple 3D observations. Timelapse geophysical monitoring technology involves aspects such as geophysical data acquisition, processing and interpretation, which is a complex systematic project.

The research in which time-lapse geophysical technology is applied to study the impact of modern coal mining on overburden strata evolution is to study overburden evolution changes during coal mining through observing and analyzing the geophysical data variations of all stages of pre-mining, mining and post-mining as well as postmining deposition stable period (Lin et al. 2011; Liu 2011; Du and Bai 2012; Zhang et al. 2014).

Considering that different geophysical prospecting approaches have their own characteristics on detection accuracy and scope and integrating with the geological condition of research area, the time-lapse geophysical monitoring of this project has chosen three geophysical prospecting methods, i.e. 3D seismic prospecting, electrical prospecting and ground penetrating radar prospecting, among which $3 \mathrm{D}$ seismic prospecting mainly aims at studying the structural changes of coal measure data (Peng et al. 2013), electrical prospecting aims at studying water bearing changes of strata (Han 2009) and ground penetrating radar aims at studying water bearing changes of shallow surface strata. It is helpful to improve the detection accuracy of geological results by organically integrating 3D seismic prospecting, electrical prospecting and ground penetrating radar prospecting and fully taking advantage of strengths of each prospecting approach.

\section{Research area overview}

The research area is located in Bulianta well field of Shendong mining area. The strata of mining area belong to North China stratigraphic area and, from old to new, have Yanchang Formation of Upper Triassic $\left(\mathrm{T}_{3 \mathrm{Y}}\right)$, Fuxian Formation of Lower Jurasic $\left(\mathrm{J}_{1 \mathrm{~F}}\right)$, Yan'an Formation of Lower-Middle Jurasic $\left(\mathrm{J}_{1-2 \mathrm{Y}}\right)$, Zhiluo Formation of Middle Jurasic $\left(\mathrm{J}_{2 \mathrm{Z}}\right)$ and Cenozoic sediments $(\mathrm{Q})$.

The strata of mining area are generally monocline strata dipping into west with a dip angle of about $1-3^{\circ}$, where faults are rare and structure is simple. The thickness of bed rock is $180-200 \mathrm{~m}$ and that of unconsolidated formation is $10-25 \mathrm{~m}$.

The mined coal seam of 12,407 working face in mining area is Coal $1^{-2}$, of which the depth is $190-220 \mathrm{~m}$, the average thickness is $4.81 \mathrm{~m}$ and the dip angle is $1-3^{\circ}$, and the coal seam is stable as well as the structure is simple.
12,407 working face stope uses approach of full-seam mining, longwall mining and caving type roof control, in which the mining height is $4.5 \mathrm{~m}$, working face length is $300 \mathrm{~m}$, the footage is $3,600 \mathrm{~m}$, the average daily mining footage is $12-13 \mathrm{~m}$ and the monthly total footage is $390-400 \mathrm{~m}$.

\section{Time-lapse data acquisition method}

The integrated time-lapse geophysical monitoring studies the spatial evolution pattern of strata and its water bearing under modern coal mining condition through repeated 3D seismic prospecting, electrical prospecting and ground penetrating radar prospecting at different time periods.

Data acquisition is chosen to be carried out in different phases of coal mining, i.e. performed before mining, during mining and in deposition stable period after mining respectively. During each data acquisition, it is required that 3D seismic prospecting, electrical prospecting and ground penetrating radar prospecting are implemented simultaneously and survey lines deployed in different prospecting methods have overlapping sections.

The duration of this time-lapse data acquisition is 10 months, the working footage positions corresponding to data acquisition time are shown in Fig. 1.

The first acquisition started in November, 2011, when Coal $1^{-2}$ of 12,407 working face hadn't been mined and the coal seam was in original state, and the acquisition was background survey for strata; the second acquisition was carried out 4 months later, when nearly half of Coal $1^{-2}$ of 12,407 working face had been mined, and half area of the working face was goaf and the other maintained unmined. Strata of goaf was in mining state and coal seams adjacent to the mining area would be influenced by mining while coal seams that were far away from the mining area maintained unmined; the third acquisition was conducted 2 months later, when Coal $1^{-2}$ of 12,407 working face had been totally mined up, and the working face became a goaf completely and the strata were in mining state; the fourth acquisition was then implemented 4 months later, when strata of 12,407 working face was totally in post-mining deposition stable period.

To observe data discrepancies resulted from coal mining activities, the time-lapse data acquisition requires data acquired in different time periods must have repeatability and the non-repetitive part should be variations resulted from mining, therefore, acquisition environment, acquisition equipment and parameters must be ensured to be repetitive when acquisition is being carried out. Based on this condition, the reliability of acquired data is guaranteed through choosing appropriate acquisition parameters and survey geometry. 
Working face mining direction

$\longrightarrow$

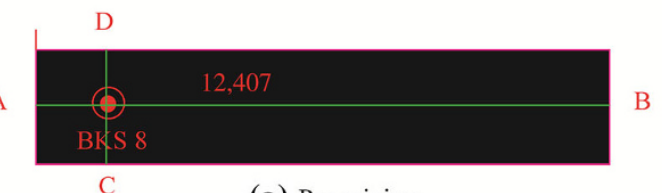

(a) Pre-mining

D

March 2012

A

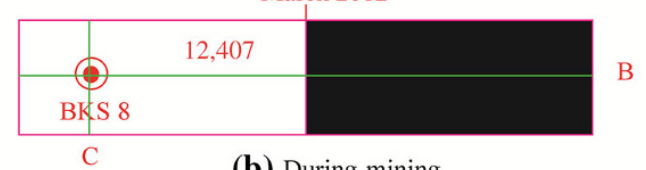

(b) During-mining

D

A

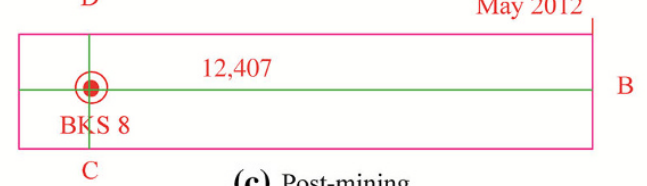

(c) Post-mining

D

A

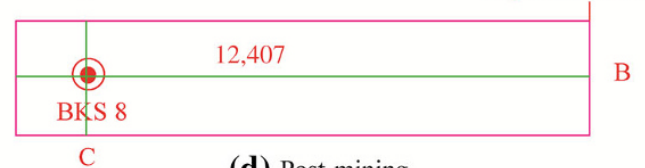

(d) Post-mining

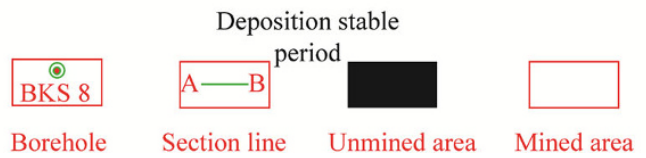

Fig. 1 Working face footage position corresponding to data acquisition time

\section{Geophysical data discrepancy analysis during coal mining}

\subsection{Seismic data discrepancy analysis}

Seismic volume can be obtained after those data acquired in 4 different time periods are processed. Figure 2 shows the seismic profile of Line $\mathrm{AB}$ along working face forwarding direction, and the major minable coal seam is located position at about $200 \mathrm{~m}$ in the vertical time section and its overlying is overburden rock strata.

Through comparison and analysis, it can be found that on the seismic profile of first acquisition data, seismic events of coal seam and their overburden strata are continuous, which indicates strata are in stable state before the coal seam is mined; on the second acquisition data, on the back of mining point, seismic events of overburden strata are chaos, which indicates coal seam mining has damaged the overburden strata, while in the front of mining point, seismic events of the coal seam and its overburden strata are continuous, which indicates the coal seam is basically not influenced by mining. On the seismic profile of the third acquisition data, the coal measure strata result in seismic events become chaos and are like lumbricoid due to coal seam mining. on the seismic profile of the fourth acquisition data, seismic evens are relatively chaos, however, compared to the seismic profile of the third acquisition data, the continuity of seismic events of overlying strata gets improved, which indicates after coal mining, the strata tend to recover over time after compacting and depositing.

\subsection{Electrical data discrepancy analysis}

Figure 3 shows geoelectrical profiles derived from processing those 4 acquired electrical data.

According to the geoelectrical profile of first acquisition, 3-4 electric strata are distributed in the underlying strata of surface; the surface has one relatively high-resistivity thin bed and 20-30 m underneath, there is one inhomogeneous low-resistivity stratum, of which the inhomogeneity is mainly influenced by topography or subsurface hydrogeological conditions; generally, the bed rock section has the resistivity distribution of coal measure strata and the roof bears water in some local areas.

On the geoelectrical profile of second acquisition, 4-5 electric strata are distributed in the underlying strata of surface, the resistivity of surface sand zone fluctuates locally, the zone 20-30 below surface generally shows a resistivity distribution of low-resistivity stratum; influenced by working face mining, the resistivity of coal roof fluctuates locally and the local resistivity of areas near mining working face increases.

Impacted by ambient conditions, the third acquisition extended survey lines by $400 \mathrm{~m}$ to the south. On the geoelectrical profile of third acquisition, 4-5 electric strata are distributed in the underlying strata of surface, the resistivity of surface strata increase relatively, the zone 20-30 below surface generally shows a resistivity distribution of lowresistivity stratum; the resistivity of coal roof influenced by working face mining fluctuates locally.

On the geoelectrical profile of second acquisition, 4-5 electric strata are distributed in the underlying strata of surface, the resistivity of strata located in the middle of survey lines is relatively higher and the sand and soil are relatively dry. The zone $20-30$ below surface generally shows a resistivity distribution of low-resistivity stratum with inhomogeneous thickness; the resistivity of coal roof fluctuates, which indicates the water content of waterbearing sandstone strata of roof decreases after mining. The resistivity of coal seam and zones near its roof decreases, which may be resulted from water charging of goaf.

\subsection{Ground penetrating radar data discrepancy analysis}

During propagation in different water-bearing formations, the energy of modern power spectra of radar signals will 


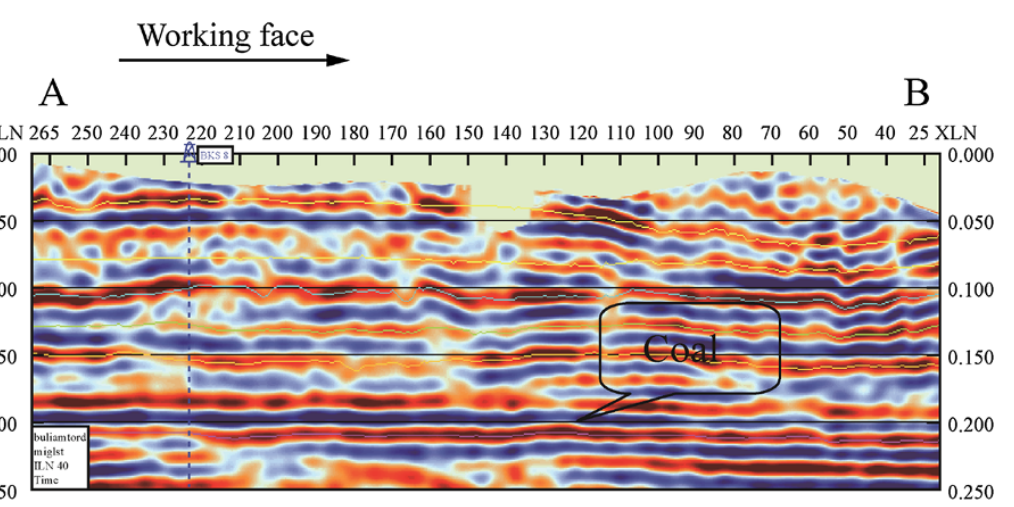

(a) $1^{\text {st }}$

A

Mining

B

XLN $26525024023022021020019018017016015014013012011010090 \quad 80 \quad 7060 \quad 50 \quad 40 \quad 25$ XLN

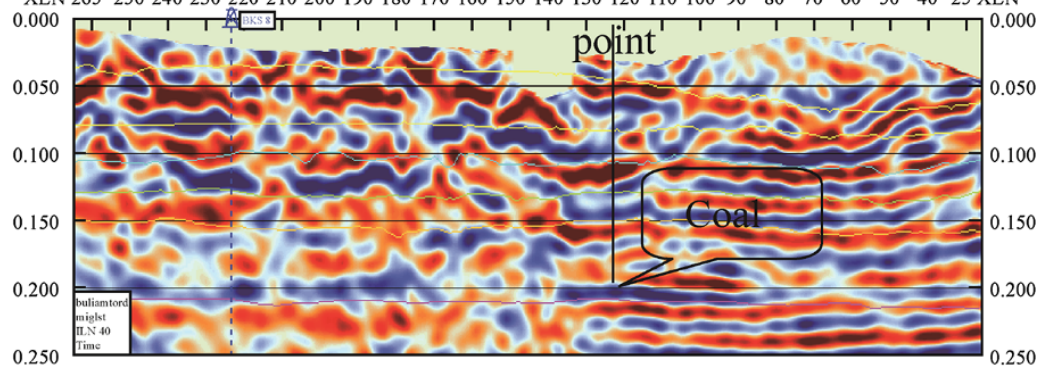

(b) $2^{\text {nd }}$

A

B

XLN $265250240230220210200190180170160150140130120110100 \quad 90 \quad 80 \quad 70 \quad 60 \quad 50 \quad 40 \quad 25$ XLN

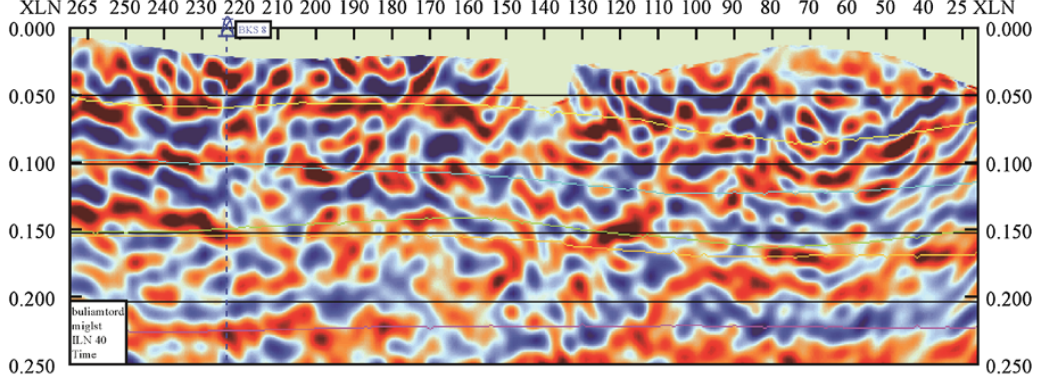

(c) $3^{\text {rd }}$

A

B

XLN $265250240230220210200190180170160150140130120110100 \quad 90 \quad 80 \quad 70 \quad 60 \quad 50 \quad 40 \quad 25$ XLN

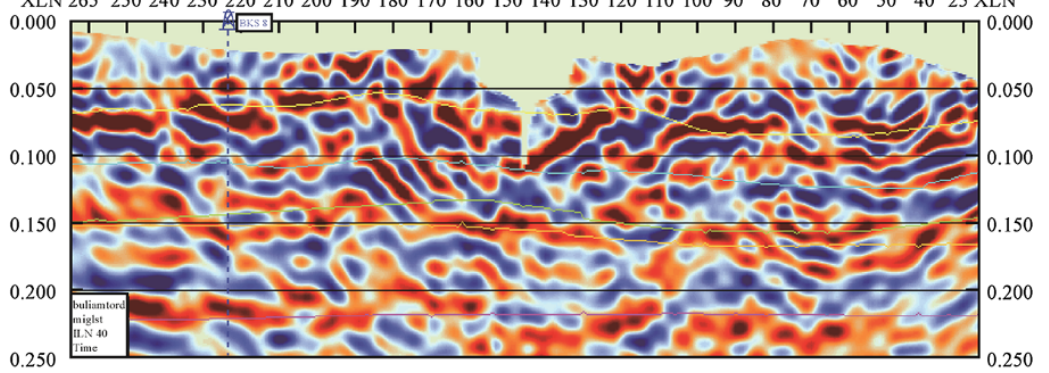

(d) $4^{\text {th }}$

Fig. 2 Seismic profiles comparison of 4 acquisition data

Amplitude 


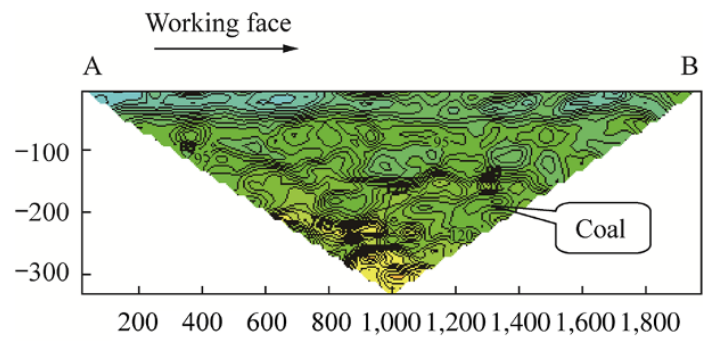

(a) $1^{\text {st }}$ acquisition

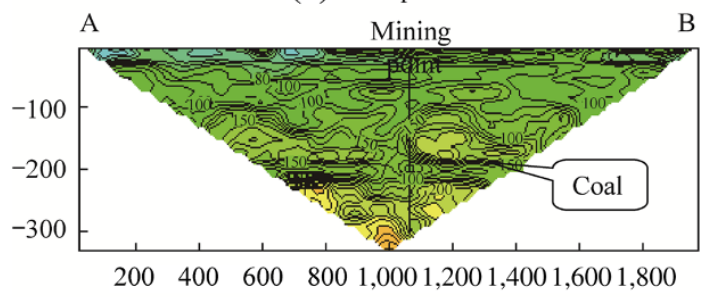

(b) $2^{\text {nd }}$ acquisition

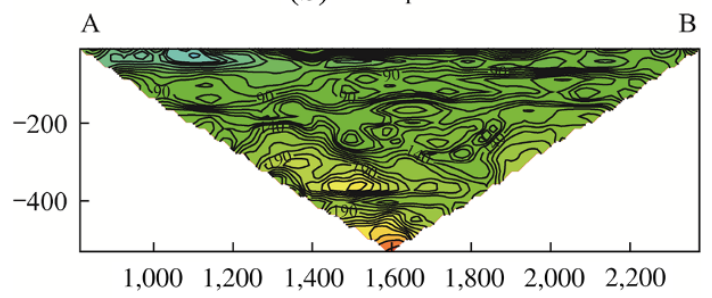

(c) $3^{\text {rd }}$ acquisition

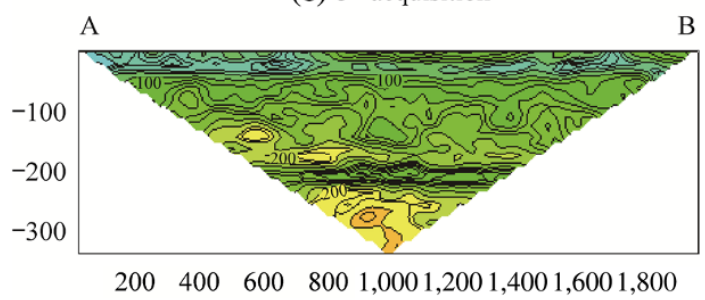

(d) $4^{\text {th }}$ acquisition

$0 \begin{array}{lllllll}50 & 65 & 75 & 85 & 95 & 110120140160180200220240300\end{array}$ Resistivity $(\Omega \cdot \mathrm{m})$

Fig. 3 Electrical profiles comparison of 4 acquisition data

changes, therefore, based on radar signals, water content of formations can be derived from inverting. Figure 4 is water content profile derived from inverting radar data, of which the depth is $0-15 \mathrm{~m}$.

It can be found through comparing those 4 acquired water content profiles that water bearing of near-surface overburden strata basically has 3 layers, i.e. water content of surface layer $(0-2 \mathrm{~m})$ is low, and water contents of middle layer $(2-8 \mathrm{~m})$ and deep layer $(8-15 \mathrm{~m})$ fluctuate due to coal mining.

When first acquisition was carried out, the coal seam was in original state, it aimed at performing background survey for surface overlying strata. The water content profile indicates that water content of surface layer is low, and that of middle layer is $12 \%-18 \%$, which indicates a good water

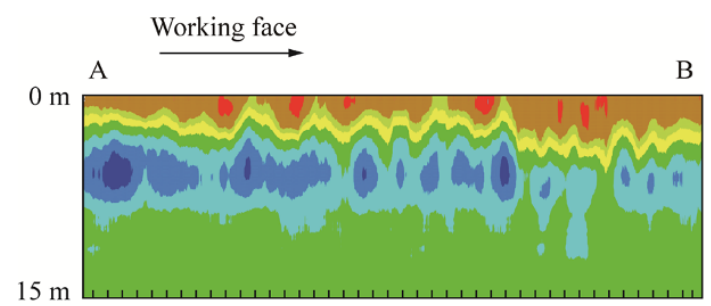

(a) $1^{\text {st }}$

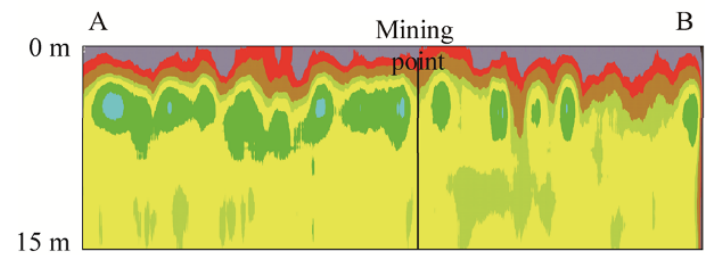

(b) $2^{\text {nd }}$

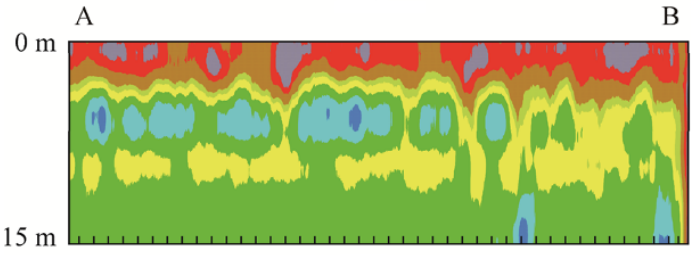

(c) $3^{\text {rd }}$

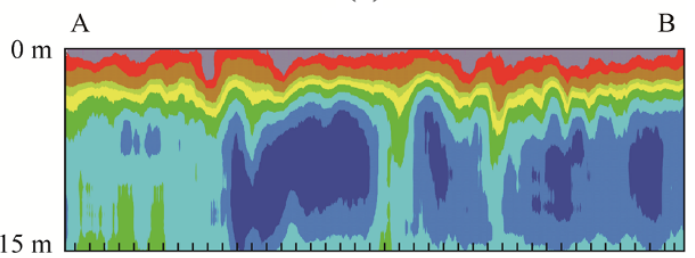

(d) $4^{\text {th }}$

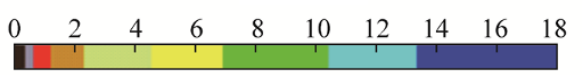

Water content $(\%)$

Fig. 4 Water content electrical profiles comparison of 4 ground penetrating radar acquisition data

content, and that of deep layer is $8 \%-10 \%$, which is a little bit lower than that of middle layer.

During the second acquisition, water contents of surface, middle and deep layers became lower significantly, the reason was that open fractures occurred in the middle layer due to disturbance of coal mining, which resulted in water content decreased. The 3-layer structure of water content of near-surface overlying strata had no significant change.

During the third acquisition, the water content of nearsurface overlying strata still had a structure of 3 layers. Water content of surface layer was lower, while that of middle and deep layers increased compared to profiles of second acquisition.

During the fourth acquisition, water content of surface layer was still lower, however, that of middle and deep layers was $8 \%-18 \%$, which significantly increased compared to the second and third acquisition. 
Working face

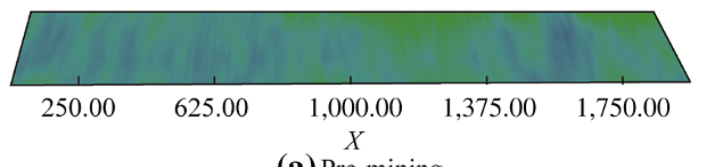

(a) Pre-mining

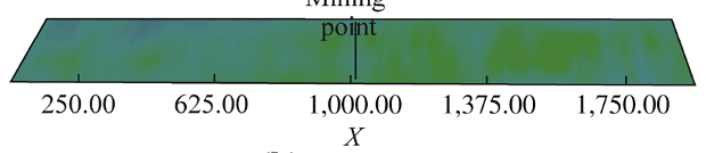

(b) During mining

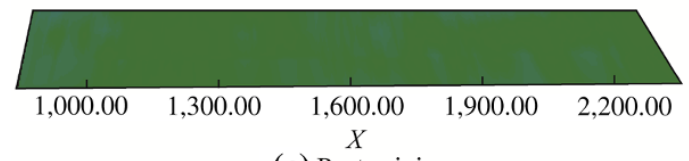

(c) Post-mining

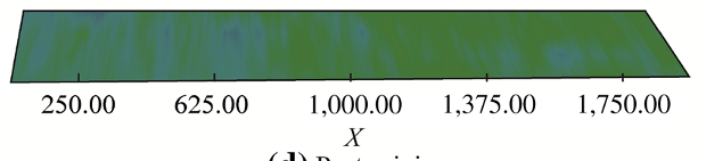

(d) Post-mining

\begin{tabular}{|c|c|c|c|c|c|c|}
\hline & 1 & $\perp$ & 1 & 1 & I & 1 \\
\hline 0 & 50 & 65 & 75 & 85 & 95 & 110 \\
\hline
\end{tabular}

Fig. 5 Electric slices comparison of far-surface aquifer during coal mining process

\section{Water bearing and stratigraphic structure variations during coal mining process}

\subsection{Stratal water bearing variation}

\subsubsection{Near-surface aquifer}

Within the research area, those surface water-bearing formations with a depth of $2-15 \mathrm{~m}$ are called near-surface aquifer. It can be found through comparing water content profiles (Fig. 4) during coal mining process that the water content of near-surface aquifer before mining (Fig. 4a) is high, after the coal seam is partly mined (Fig. 4b), water content decreases, water bearing deteriorates, when the coal seam is completely mined up, water content of zones in the back of mining point is significantly larger than that of zones in the front due to mining influence. After the coal seam is totally mined, the strata endure deposition stable period and water bearing recovers to the state before mining, which indicates water bearing of near-surface aquifer has obvious recovery trend over time after mining.

\subsubsection{Far-surface aquifer}

Within the research area, those surface water-bearing formations with a depth of $15-50 \mathrm{~m}$ are called far-surface aquifer. It can be found through comparing electric slices
Working face

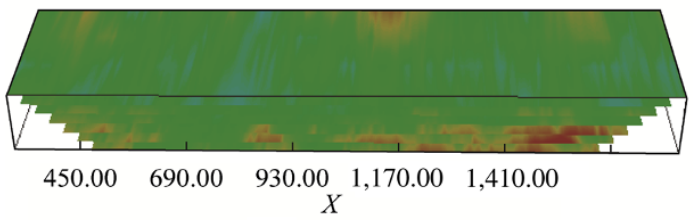

(a) Pre-mining

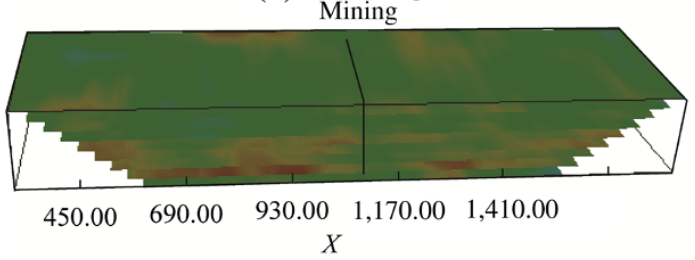

(b) During mining

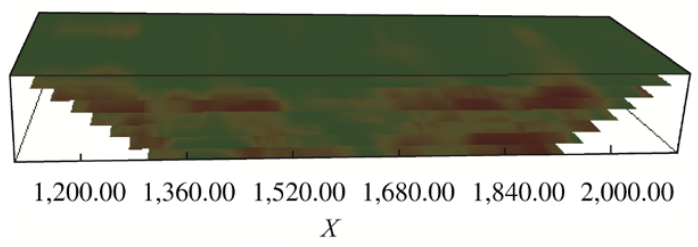

(c) Post-mining

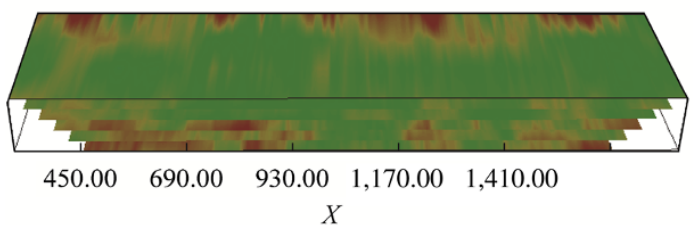

(d) Post-mining

Fig. 6 Electric slices comparison of roof aquifer during coal mining process

(Fig. 5) of far-surface aquifer during coal mining that before mining, due to Buliangou exists in the middle of farsurface aquifer (Fig. 5a), its underlying strata are water saturated and water bearing of other zones is poor; during mining (Fig. 5b, c), mining activities lead to electric property changes of subsurface aquifers, the resistivity increases a little bit and water bearing deteriorates in general; during post-mining deposition stable period (Fig. 5d), resistivity of subsurface aquifer decreases and its water-bearing distribution basically recovers to the premining state.

\subsubsection{Water bearing of roof}

Figure 6 shows the electric slices of roof aquifer during coal mining. It can be found through comparison that before mining, the roof has multiple inhomogeneous aquifers (Fig. 6a), of which the local water bearing is good; when influenced by mining (Fig. 6b, c), roof water 


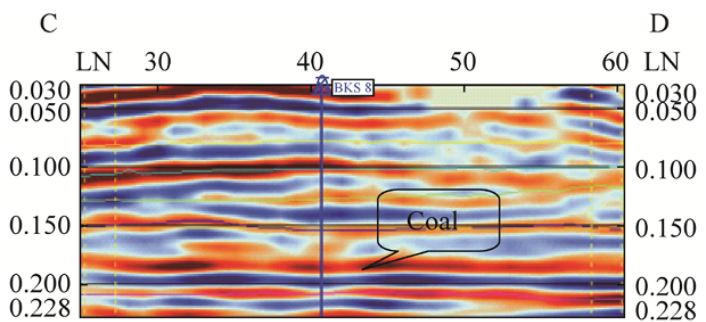

(a) Pre-mining

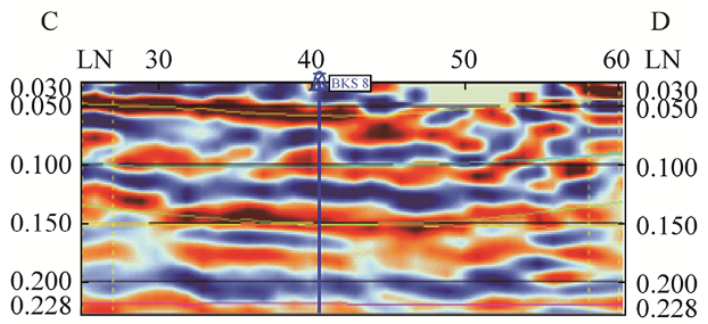

(b) During

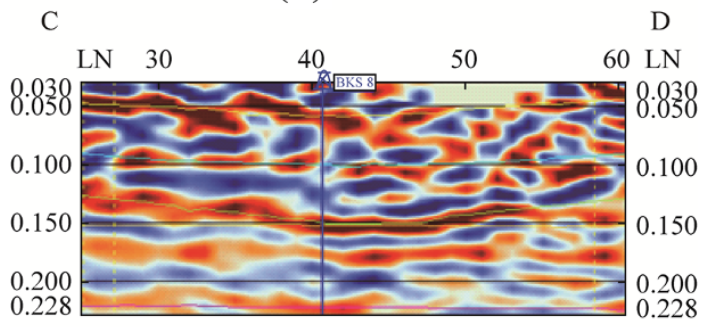

(c) Post-mining

C

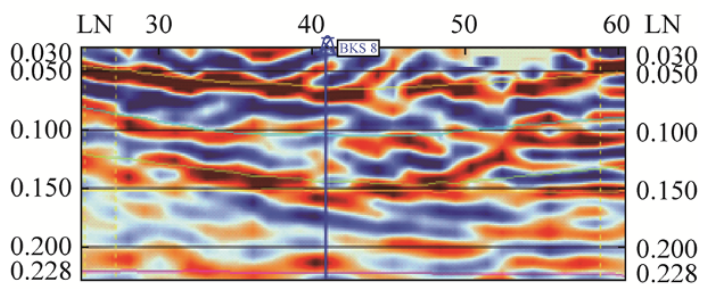

(d) Post-mining

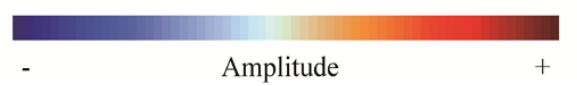

Fig. 7 Seismic profile comparison during coal mining process

infiltrates downward and roof resistivity generally increases, the water bearing of roof aquifer deteriorates, after post-mining deposition stable period, water bearing of roof doesn't recover (Fig. 6d) and generally is poor.

\subsection{Stratigraphic structure variations}

Figure 7 shows the seismic profile of Line CD which is perpendicular to the working face forwarding direction. When the coal seam is unmined (Fig. 7a), strata from the surface to the target coal seam are stable, of which the seismic events also are continuous. After the coal seam is mined (Fig. 7b), the far-surface strata begin to bend and the reflection waves of coal roof are chaos. Compared to strata
Working face

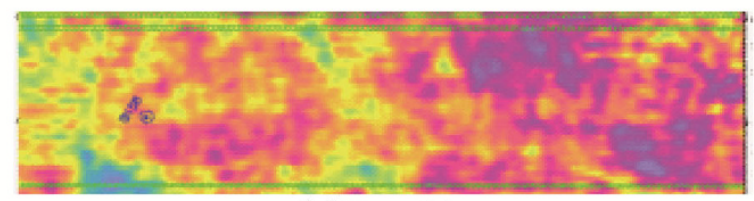

(a) Pre-mining

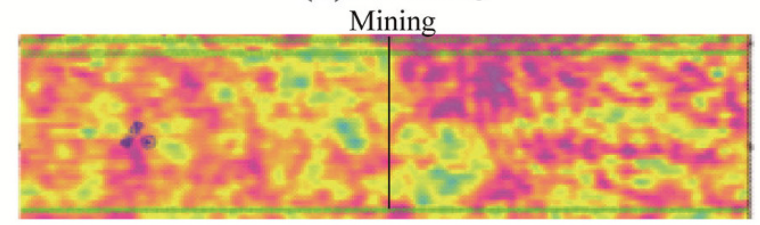

(b) During mining

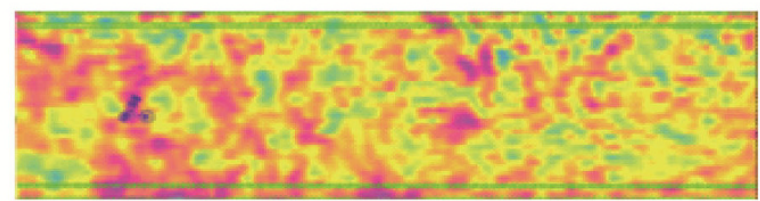

(c) Post-mining

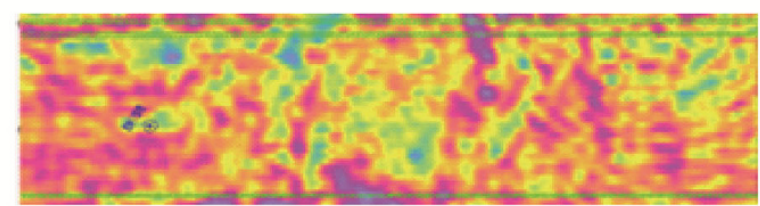

(d) Post-mining

$\begin{array}{ccccccccc}1 & 1 & 1 & 1 & 1 & 1 & 1 & 1 \\ -6,000-5,000-4,000-3,000-2,000-1,000 & 0 & 1,000 & 2,000 & 3,000 & 4,000 & 5,000 & 6,000\end{array}$ Amplitude

Fig. 8 Comparison of amplitude strata slices of coal roof during coal mining

before mining, roof strata collapse or generate fractures due to mining activities, which leads to seismic waves are absorbed when propagating in the strata and seismic wave frequency also decreases. After 2 months' coal mining (Fig. 7c), the seismic wave frequency of coal roof increases and seismic waves become more continuous, which indicates the strata endure compaction and porosity decreases; the reflection waves of far-surface strata are lumbricoid, which indicates fractures still exist. After 4 months' deposition stable period (Fig. 7d), the seismic frequency of near-surface strata increases significantly compared to that of coal roof strata, which indicates the self-heal capability of near-surface strata is stronger than that of coal roof strata.

The amplitude stratal slices (Fig. 8) of coal roof during coal mining show that before mining, amplitudes of coal roof (Fig. 8a) generally are stable and have a trend of strengthening along working face forwarding direction; during mining (Fig. 8b), the amplitudes of coal roof in the back of mining point become weak due to mining activities, and that of coal roof in the front are still strong due to the coal seam is unmined; after coal mining (Fig. 8c), due 
to mining activities, amplitudes of coal roof become weak, and after deposition stable period, the coal roof amplitudes (Fig. 8d) increase, which indicates after the coal seam is mined and long-term compaction, the coal roof recovers to a certain extent.

\section{Conclusions}

Based on time-lapse geophysical monitoring technology, the integrated analysis for water bearing and stratigraphic structure of strata in modern coal mining process utilizing seismic data, electrical data and ground penetrating radar data reaches the following conclusions:

(1) In modern coal mining process, water bearing property of surface formations has self-healing trend. In general, water content of near-surface strata is relatively low before mining, influenced by coal mining, water contents of near-surface formations decrease after the formations begin to loose, after long-term (10 months) recovery, fractures of the near-surface strata become more developed and conductivity increases, fissure water of near-surface strata filtrates downward and water content increases. Influenced by coal mining, resistivity of far-surface aquifer increases in the mining process, in post-mining deposition stable period, local ground water of the aquifer infiltrates, resistivity decreases, and its water bearing basically recovers to the premining state. Water bearing of coal roof become worse during mining. This indicates that water bearing self-healing capability of near-surface strata is higher, while that of roof strata adjacent to the coal seam mined is lower.

(2) Stratigraphic structure has self-healing trend over time in modern coal mining process. After coal mining begins, the far-surface strata bend, influenced by mining collapse or fractures, the reflected seismic waves are absorbed by strata and frequency significantly decreases. After 10 months' deposition stable period, the frequency of near-surface seismic waves significantly increases compared to that of coal roof, which indicates self-healing capability of near-surface strata is higher, while that of coal roof strata is lower.

Acknowledgments Foundation Program: National Science and Technology Supporting Program (2012BAB13B01), National Key
Scientific Instrument and Equipment Development Program (2012YQ030126), Coal United Project of National Natural Science Foundation (U1261203), China Geological Survey Project (1212011220798), National Science and Technology Major Project (2011ZX05035-004-001HZ).

Open Access This article is distributed under the terms of the Creative Commons Attribution License which permits any use, distribution, and reproduction in any medium, provided the original author(s) and the source are credited.

\section{References}

Du F, Bai HB (2012) Mechanism research of overlying strata activity with fully mechanized caving in thin bedrock with thick alluvium. J China Coal Soc 37(7):1105-1110

Du WF, Peng SP (2014) 4D seismic data acquisition method during coal mining. J Geophys Eng 11:035005

Gu DZ (2013) Water resource and surface ecology protection technology of modern coal mining in China's energy "Golden Triangle". China Eng Sci 15(4):102-107

Gu DZ, Zhang JM (2012) Modern coal mining affected to underground water deposit environment in West China mining area. Coal Sci Technol 40(126):114-117

Gu DZ, Zhang JM, Wang ZR, Cao ZG, Zhang K (2013) Observations and analysis of groundwater change in Shendong mining area. Coal Geol Explor 41(4):35-39

Han DP (2009) Geology-electricity-temperature multi parameter synthesized leading detection technology and applications. J China Coal Soc 34(11):1501-1505

Lin HF, Li SG, Cheng LH, Wang HS (2011) Experimental analysis of dynamic evolution model of mining-induced fissure zone in overlying strata. J Min Saf Eng 28(2):299-303

Liu CG (2011) Similar simulation study on the movement behavior of overlying strata in shallow seam mining in Majiliang Coal Mine. J China Coal Soc 36(1):7-11

Peng LY, Cui RF, Ren C, Cui DW (2013) Classification of coal body structure using seismic lithology inversion information. J China Coal Soc 38(Supp2):410-415

Wang KY, Yun MH, Zhang XM (2008) Study and application of time-lapse seismic monitoring for the thermal recovery of heavy oil reservoir. Prog Geophys 23(1):157-161

Zhang JM, Yang JZ, Zhang K (2012) Study on the 4D high-precision detection method for groundwater variation under modern coal mining. Shenghua Technol 10(6):27-30

Zhang JM, Li P, Gao L (2013a) Research on structural damage of mining overburden oversized fully mechanized coal mining face. Shenghua Technol 11(4):20-23

Zhang JM, Yang F, Li NK, He RM (2013b) Aqueous self-healing of surface layer in mining area of super-large mechanized face. Coal Geol Explor 41(4):35-39

Zhang HW, Zhu ZJ, Huo LJ, Chen Y, Huo BJ (2014) Overburden failure height of superhigh seam by fully mechanized caving method. J China Coal Soc 39(5):816-821

Zhao GS (2005) The status and outlook of dynamic reservoir monitoring: time-lapse seismic. Prog Explor Geophys 28(3):157-168 